\section{Hematological profile in visceral leishmaniasis}

\author{
Agrawal Y,1* Sinha AK,1 Upadhyaya P,1 \\ Kafle SU, ${ }^{1}$ Rijal S, ${ }^{2}$ Khanal B ${ }^{3}$
}

\begin{abstract}
${ }^{1}$ Department of Pathology, 2Department of Medicine, ${ }^{3}$ Department of Microbiology, B.P. Koirala Institute of Health Sciences, Dharan, Nepal
\end{abstract}

*Correspondence to: Dr. Yamuna Agrawal, Departments of Pathology, B.P. Koirala Institute of Health Sciences, Dharan, Nepal yamunaagrawal @yahoo.com, Tel. No.: (+977) 9841527589

\begin{abstract}
INTRODUCTION: Visceral Leishmaniasis is the most severe form of leishmaniasis and can be fatal in the absence of treatment. Nepal, India, Bangladesh, Brazil and Sudan constitute five countries of the world where more than $90 \%$ of visceral leishmaniasis occurs. The aim of this study is to evaluate haematological profile with available clinical data in visceral leishmaniasis patients and to detect LD bodies among them.
\end{abstract}

MATERIALS AND METHODS: It is a hospital based cross sectional study conducted in the Department of Pathology, BPKIHS, Dharan, for the period of one year. LD bodies were calculated in bone marrow aspirate of forty clinically suspected cases by counting the number of parasites per 100 consecutive oil immersion fields.

RESULTS: The age ranged from 2-60 years. Pyerxia was the most common sign (100\%) followed by splenomegaly $(82.5 \%)$, hepatomegaly $(65 \%)$, and pallor $(75 \%)$. Anemia was present in $90 \%$, leucopenia in $67.5 \%$ and thrombocytopenia in $72.5 \%$ cases. Bicytopenia and pancytopenia were observed in $40 \%$ and $25 \%$ cases, respectively. On peripheral examination RBCs were predominantly normocytic normochromic. On bone marrow examination normocellular marrow and megaloblastic features were predominant findings followed by increased plasma cells. Low, moderate and high grade LD bodies were present in $7.5 \%, 37.5 \%$ and $55 \%$ of the cases respectively. Hepatomegaly, anemia, neutropenia and lymphocytosis were statistically significant to parasite load ( $\mathrm{p}$-value $<0.05$ ).

CONCLUSIONS: Besides LD bodies in bone marrow aspirates, dyserythroblastic changes and increase plasma cells are common findings in leishmaniasis. Patient from endemic area with positive clinical history and findings should be examined for LD bodies in marrow if dyserythroblastic and increase plasma cell picture is found.

KEY WORDS: Visceral leishmaniasis, Bone marrow aspiration, LD bodies

Article submitted 10 April. Reviewed 12 May. Author correction 20 May. Final version accepted 28 May 2013 


\section{INTRODUCTION}

Visceral Leishmaniasis (VL) was first described in 1903 by Leishman and Donovani. VL is endemic in over 60 countries. The incidence is estimated at 100,000 cases each year. ${ }^{1}$ Leishmania is capable of causing spectrum of clinical syndromes like cutaneous leishmaniasis, mucocutaneous leishmaniasis and visceral leishmaniasis. VL is the most severe form of leishmaniasis and it can be fatal in the absence of treatment. ${ }^{2}$ Visceral leishmaniasis also known as kala-azar is an infection produced by obligate intracellular kinetoplastid protozoa through accidental bite of infected sandflies. ${ }^{3}$ Nepal together with India, Bangladesh, Brazil and Sudan constitutes the five countries of the world more than $90 \%$ of VL occurs. In Nepal the disease affects the Eastern terai region which lies adjacent to the Bihar State of India. ${ }^{4}$ This condition constitutes a major health problem in Nepal. It is the second largest parasitic killer in the world after malaria. ${ }^{5} \mathrm{~A}$ large number of patients are referred for diagnosis and treatment in B. P Koirala institute of Health Sciences (BPKIHS), Dharan a referral tertiary teaching hospital located in the Eastern part of Nepal. When the patient has not come from a known endemic area, the clinical picture can confuses with a number of conditions that occur more commonly and without the suspicion of kala azar. There is high chance of missing leishmania Donovan (LD) bodies in the bone marrow examination. ${ }^{6}$

In the present study we have tried to evaluate haematological parameters and bone marrow examination with available clinical data on the haematology request form which will bring about a high degree of suspicion for haematologists to look for LD bodies in the bone marrow examination. The relation between parasite load and complete blood count is also accessed in this study.

\section{MATERIAL AND METHODS}

This was a hospital based cross sectional study conducted in the department of Pathology at BPKIHS, Dharan, Nepal for the period of one year. All clinically diagnosed case of visceral leishmaniasis visiting BPKIHS and cases who agree to have investigations (complete blood count, peripheral smear and bone marrow examinations) were included in the study. Cases who did not agree to have investigations were excluded. Total of 40 cases were included after each case meeting the inclusion criteria and in each patient complete blood count; peripheral smear and bone marrow aspiration were done.
The parasite loads of LD bodies were calculated in bone marrow aspirate by counting the number of parasites (LD bodies per 100 consecutive oil immersion fields $\{0 I F\})$. Parasite load were graded as follows: high grade ( $>30 \mathrm{LD}$ bodies/100 OIF), moderate grade (10-30 LD bodies/100 OIF) and low grade $(<10$ LD bodies/100 OIF). The obtained data were compiled in computer and analysed using Statistical Package for Social Science ( SPSS v. 17.0). A p-value of 0.05 or less was considered statistically significant.

\section{RESULTS}

This was a cross sectional study conducted on $40 \mathrm{LD}$ bodies positive cases over the period of one year. The age ranged from 2-60 years with mean age 16.5 years. Male (55\%) affected predominantly than females (45\%). Students and farmers were the most affected group which comprised of 55\%. Morang district was the largest case residence area. The overall sociodemographic representation is shown in (Table1) below. Pyrexia were the most common sign present in all cases $(100 \%)$ as shown in (Table 2) followed by splenomegaly (82.5\%), hepatomegaly (65\%), and pallor (75\%) as shown in (Table 3). Anemia was present among 90\% cases and leucopenia and thrombocytopenia were present in $67.5 \%$ and $72.5 \%$ respectively. Bicytopenia was observed in $40 \%$ of cases, where as pancytopenia in $25 \%$. On peripheral examination normocytic normochromic and anisocytosis with hypochromic features of RBC were most common findings as shown below in (Table 4).

On bone marrow examination normocellular marrow and megaloblastic changes were predominant findings followed by increased plasma cells. Megaloblastic anemia was observed in 55\%.

LD bodies were counted in 100 per oil immersion field in bone marrow aspiration and graded as low $(\leq 10)$, moderate $(10-30)$ and high grade $(>30)$ as shown in (Table 5) below. Low, moderate and high grade LD bodies were present in $7.5 \%, 37.5 \%$ and $55 \%$ of the cases respectively.

\section{DISCUSSION}

Kala azar is an endemic public health problem in tropical and subtropical region of Nepal especially affecting people of rural communities. Recent resurgence of kala azar in the rural population of the Southern terai of Nepal (11 districts) adjoining the border of kala azar endemic areas of Bihar in India now poses a mojor health problem. ${ }^{8}$ According to World Health Organization (WHO), leishmania 
affect two million people annually, 500,000 cases of which are of visceral form. It is estimated that 350 million people are exposed to the risk of infection, with a global prevalence of 12 million infected individuals. ${ }^{15}$ More than 5.5 million people are estimated to be at risk of the disease and presently 12 districts in Southern plains of terai region in Nepal-boarding the state of Bihar-and few more

Table 1. Socio-demographic characteristics of Kala-azar patients admitted at BPKIHS

\begin{tabular}{|c|c|c|c|}
\hline Characteristics & Categories & $\mathbf{n}$ & $\%$ \\
\hline \multirow{3}{*}{$\begin{array}{l}\text { Age } \\
\text { (years) }\end{array}$} & $2-15$ & 14 & 35.0 \\
\hline & $16-30$ & 14 & 35.0 \\
\hline & $\geq 30$ & 12 & 30.0 \\
\hline \multirow{2}{*}{ Sex } & Male & 22 & 55.0 \\
\hline & Female & 18 & 45.0 \\
\hline \multirow{5}{*}{ Occupation } & Pre school & 5 & 12.5 \\
\hline & Farmer & 11 & 27.5 \\
\hline & Housewife & 7 & 17.5 \\
\hline & Labour & 6 & 15.0 \\
\hline & Student & 11 & 27.5 \\
\hline \multirow{6}{*}{ District } & Jhapa & 4 & 10.0 \\
\hline & Morang & 20 & 50.0 \\
\hline & Saptari & 7 & 17.5 \\
\hline & Siraha & 1 & 2.5 \\
\hline & Sunsari & 6 & 15.0 \\
\hline & Udayapur & 2 & 5.0 \\
\hline
\end{tabular}

Table 2. Presenting complains of kala azar patients admitted at BPKIHS

\begin{tabular}{llcc}
\hline Complains & Categories & $\mathrm{n}$ & $\%$ \\
\hline \multirow{2}{*}{ Weight loss } & Present & 28 & 70 \\
& Absent & 12 & 30 \\
Loss of appetite & Present & 27 & 67.5 \\
& Absent & 13 & 32.5 \\
Fever & Present & 40 & 100.0 \\
Other disease & Absent & 0 & 0.0 \\
(TB) & Present & 1 & 2.5 \\
\hline
\end{tabular}

Table 3. On examination findings of the Kala-azar patients admitted at BPKIHS

\begin{tabular}{llcc}
\hline On Examination & Categories & $\mathrm{n}$ & $\%$ \\
\hline \multirow{2}{*}{ Pallor } & Present & 30 & 75.0 \\
& Absent & 10 & 25.0 \\
\multirow{2}{*}{ Temperature $\left({ }^{\circ} \mathrm{F}\right)$} & $97-99$ & 19 & 47.5 \\
& $100-102$ & 21 & 52.5 \\
\multirow{2}{*}{ Splenomegaly } & Absent & 7 & 17.5 \\
& Present & 33 & 82.5 \\
\multirow{2}{*}{ Hepatomegaly } & Absent & 14 & 35.0 \\
& Present & 26 & 65.0 \\
\hline
\end{tabular}

district showing sporadic cases. ${ }^{12}$

In this study the common age group was below 30 years. $50 \%$ of this group was below 15 years and remaining $50 \%$ was of above 15 years. This finding was similar to Uzair $\mathrm{M}$ et $a l^{2}$ and Benzamine B et al. ${ }^{9}$ In contrast, Hamid GA et al ${ }^{18}$, Canatan D et al ${ }^{19}$, Petrela R et al ${ }^{20}$ and Singh K et $a l^{12}$, had age groups below five years. VL is not only the problem of children but is also common in adolescent and adult.

Male sex predominance was reported by Uzair M et $a l^{2}$, Rai ME et $a l^{16}$ and Saqur I et $a l^{17}$ but Hamid GA et al ${ }^{18}$ reported female sex predominace. The gender variation has no association with VL so this was not a significant finding for us. We observed, visceral leishmaniasis is more common among student, farmer, labour and housewife. Kala-azar is problem of working population of the country.

The majority of cases of kala azar seen in our study were from Eastern Nepal such as Morang, Sunsari and Saptari. Similar study was done by Singh K et al. ${ }^{12}$ The condition affects the poorest of the poor section of people residing in this part of Nepal. Concentrated cases lie nearby to BPKIHS which is not an accidental finding as BPKIHS is only the treatment centre in Eastern reagion hence cases from Eastern district are least likely to be missed.

Past history and family history of kala azar was observed in visceral leishmaniasis patients in this study. This finding showed that the preventive majors that break the chain of transmission may not be effective.

The major sign was pyrexia in 40 patients $(100 \%)$, similar result was reported by Dash S et $\mathrm{al}^{6}$, Hamid GA et $a l^{18}$ and Uzair M. ${ }^{2}$ Other disease like tuberculosis was observed in 1 patient (2.5\%). Positive findings like pallor, splenomegaly, hepatomegaly were observed but less common than to the Dash S et $\mathrm{al}^{7}$ and Hamid GA et al. ${ }^{18}$

Visceral leishmaniasis should be strongly suspected in patients with unexplained fever, being longer than 2 weeks, pallor, splenomegaly, hepatomegly and potential exposure in an endemic area or from areas from where 
Table 4. Relationship between parasite load and others related variables

\begin{tabular}{|c|c|c|c|c|c|}
\hline \multirow{2}{*}{ Variable } & \multirow{2}{*}{ Categories } & \multicolumn{3}{|c|}{ Parasite Load } & \multirow{2}{*}{ p-value } \\
\hline & & Mild & Moderate & Severe & \\
\hline \multirow{4}{*}{ Age (in years) } & $1-15$ & 0 & 5 & 9 & \multirow{4}{*}{0.710} \\
\hline & $15-30$ & 1 & 5 & 8 & \\
\hline & $\geq 30$ & 1 & 6 & 5 & \\
\hline & Female & 1 & 4 & 13 & \\
\hline \multirow{2}{*}{ Splenomegaly } & Present & 3 & 11 & 19 & \multirow{2}{*}{0.420} \\
\hline & Absent & 0 & 4 & 3 & \\
\hline \multirow{2}{*}{ Hepatomegaly } & Present & 1 & 7 & 18 & \multirow{2}{*}{0.043} \\
\hline & Absent & 2 & 8 & 4 & \\
\hline Bicytopenia & Present & 1 & 7 & 8 & \\
\hline Pancytopenia & Present & 1 & 2 & 7 & 0.936 \\
\hline Normal & Present & 0 & 7 & 7 & \\
\hline \multirow{2}{*}{ Platelet } & Adequate & 0 & 5 & 10 & \multirow{2}{*}{0.286} \\
\hline & Inadequate & 3 & 10 & 12 & \\
\hline Hemoglobin & & $7 \pm 2.15$ & $9.06 \pm 1.85$ & $7.114 \pm 2.1$ & 0.018 \\
\hline TLC & & $3033.33 \pm 1662.3$ & $4396 \pm 3179.7$ & $3709.09 \pm 2588.1$ & 0.652 \\
\hline \multirow{5}{*}{ CBC } & Neutrophil & $37 \pm 13.9$ & $52.6 \pm 12.7$ & $46.73 \pm 13.5$ & 0.144 \\
\hline & Lymphocyte & $60.33 \pm 15.9$ & $42.53 \pm 12.6$ & $48.77 \pm 13.9$ & 0.101 \\
\hline & Monocyte & & $5.45 \pm 2.8$ & $5.13 \pm 2.1$ & 0.729 \\
\hline & Eosinophils & & $4.33 \pm 3.2$ & $4.4 \pm 1.9$ & 0.999 \\
\hline & Platelets & & $113200 \pm 44091.14$ & $115150 \pm 77261.34$ & 0.995 \\
\hline \multirow{4}{*}{ Peripheral smear } & Neutrophil & $61.33 \pm 22.12$ & $54.4 \pm 12.15$ & $41.14 \pm 14.82$ & 0.010 \\
\hline & Lymphocyte & $36.33 \pm 24.50$ & $41.2 \pm 12.32$ & $54.77 \pm 15.14$ & 0.014 \\
\hline & Monocyte & 6.0 & $3.82 \pm 1.66$ & $3.8 \pm 2.48$ & 0.620 \\
\hline & Eosinophil & 1.0 & $2.3 \pm 1.06$ & $2.5 \pm 1.20$ & 0.467 \\
\hline
\end{tabular}

Table 5. Relationship between parasite load and bone marrow findings

\begin{tabular}{|c|c|c|c|c|c|}
\hline \multirow{2}{*}{ Bone marrow } & \multirow{2}{*}{ Categories } & \multicolumn{3}{|c|}{ Parasite Load } & \multirow{2}{*}{$\mathrm{p}$-value } \\
\hline & & Mild & Moderate & Severe & \\
\hline \multirow{3}{*}{ Cellular } & Normocellular & 2 & 12 & 19 & \multirow{3}{*}{0.241} \\
\hline & Hypocellular & 1 & 3 & 3 & \\
\hline & Diluted & 0 & 0 & 0 & \\
\hline \multirow{2}{*}{ Megaloblastic changes } & Present & 2 & 8 & 12 & \multirow{2}{*}{0.912} \\
\hline & Absent & 1 & 7 & 10 & \\
\hline \multirow{2}{*}{$\begin{array}{l}\text { Dyserythropoietic } \\
\text { feature }\end{array}$} & Present & 1 & 3 & 12 & \multirow{2}{*}{0.106} \\
\hline & Absent & 1 & 12 & 10 & \\
\hline \multirow{2}{*}{ Giant MC/MMC } & Present & 1 & 2 & 7 & \multirow{2}{*}{0.418} \\
\hline & Absent & 1 & 13 & 15 & \\
\hline \multirow{2}{*}{ Plasma cell } & $\leq 2$ & 1 & 6 & 9 & \multirow{2}{*}{0.936} \\
\hline & $>2$ & 1 & 10 & 13 & \\
\hline
\end{tabular}

leishmaniasis has been reported.

On complete blood count (CBC), the majority of patients had anemia, leucopenia, and thrombocytopenia $(90 \%, 67.5 \%$ and $72.5 \%$, respectively) followed by neutropenia $(27.5 \%)$, and lymphocytosis (65\%). Similar finding were observed by various authors such as Dash $\mathrm{S}$ et $\mathrm{al}^{7}$, Singh $\mathrm{K}$ et $a \mathrm{l}^{12}$ and Petrela $\mathrm{R}$ et al. ${ }^{20}$ series have reported a normocytic normochromic anemia in peripheral smear examination. ${ }^{11,13,14}$
In this study we observed normocytic normochromic and anisocytosis hypochromic in equal frequency (35\%) followed by anisopoikilocytosis hypochromia (20\%), normocytic hypochromia (5\%) and anisopoikilocytosis normochromic $(2.5 \%)$. This varying degree of anemia was present in all cases with a multifactorial etiology of which nutritional factors might be common one.

Dash $\mathrm{S}$ et $a l^{6}$ also observed anisocytosis in the 
in the peripheral smear in the form of microcytes and macrocytes in $25 \%$ of cases. Contrast to CBC, peripheral smear showed that more lymphocytosis (95\% versus 65\%) and less thrombocytopenia $(37.5 \%$ versus $72.5 \%)$ in our study.

Pancytopenia was the most frequent haematological abnormality in others study, 2,7,27,28 which comprised of $80 \%, 54 \%, 70.3 \%$ and $48 \%$, respectively. Contrast to our study, bicytopenia (40\%) was the commonest finding than pancytopenia $(25 \%)$ in the peripheral smear examination. It could be due to long duration of symptoms and splenomegaly before presentation to the hospital and increased peripheral destruction rather than bone marrow failure of production as suggested by the bone marrow hyperplasia.

In this study we observed normal to hypocellular cellularity in bone marrow aspiration in 95\% cases. Similar study was done by Dash $\mathrm{S}$ et al, 6 and Marwaha $\mathrm{N}$ et $a l^{7}$ where normal to hypercellular bone marrow cellularity has been reported. Dyserythropoietic features were observed in $40 \%$, megaloblastic changes in $55 \%$ and giant myelocyte and metamyelocyte in $40 \%$ of cases. Similar study done by Sinha AK, ${ }^{15}$ Dash S et al ${ }^{7}$ and Marwaha N et $a l^{7}$ showed megaloblastic maturation in erythroid series and giant metamyelocytes in myeloid series. This dyserythropoiesis and dysmyelopoiesis observed in our cases were consistent with the degree of megaloblastosis present, where megaloblastic anemia were observed in $55 \%$ of cases due to malnutrition and poverty, diversion of haematinic factors from the haemopoietic to the parasitic compartment.

In marrow plasma cells were increased in $60 \%$ of cases, which is similar to reports published. 6,19 This plasma cell percentages can provide a good lead towards suspicion of VL. Diagnosis of VL is made by means of visualizing the organism in Giemsa stained smears of bone marrow. Examination of bone marrow is an easy method to establish the diagnosis of VL.6,10,20,21 This study also confirmed the diagnoses of patients based on examination of bone marrow.

Hepatomegaly, anemia, leucopenia and lymphocytosis on peripheral smear had significant relationship with parasite load but did not have significant relationship with platelet and others variables from the bone marrow examination. Marwaha $\mathrm{N}$ et al $^{7}$ found that the hemoglobin level and platelet count were related to parasite load, on the other hand Hamid GA et al ${ }^{18}$ found increase in in the parasite load in children with severe anemia, leucopenia and thrombocytopenia. But no relationship of hepatomegaly and bone marrow has been shown with parasite load by other authors.

\section{CONCLUSION}

This study showed that VL, is a recognized problem particularly in Eastern Nepal. So the Ministry of health should be aware of the condition in order to improve environmental, sanitation and personal protective measures. With this kind of clinical peripheral smear and bone marrow picture, the hematologist should patiently look for LD bodies in the bone marrow for the diagnosis of $\mathrm{VL}$.

CONFLICT OF INTEREST: None to declare.

FINALCIAL INTEREST: None to declare.

\section{REFERENCES}

1. WHO Recommended Surveillance Standards, 2nd ed. 1999 Oct;WHO/CDS /CSR/ISR/99.2.

2. Uzair M, Khan SJ, Munib S, Raheem F, Shah SH. Visceral leishmaniasis (Kala-azar): presentation, diagnosis and response to therapy. Gomal J Medical Sci 2004;2:9-12.

3. Titus RG, Ribeiro JM. Salivary gland lysates from the sand fly Lutzomyia longipalpis enhance Leishmania infectivity. Science 1988;239:1306-1308.

4. Joshi DD, Sharma M, Bhandari S, Visceral leishmaniasis in Nepal during 1980-2006. J Commune Dis 2006;38:139148.

5. Singh K, Singh R, Parija SC, Faridi MMA, Bhatta N. Clinical and laboratory study of kala-azar in children in Nepal. J Trop Pediatr 1999;45:95-97.

6. Dash S, Awasti A, Marwaha RK. Haematological profile of childhood visceral leishmaniasis. Indian J pathol 2005; 8:4-6.

7. Marwaha N, Sarode R, Gupta RK, Garewal G, Dash S. Clinco-hematological characterstics in patients with kalaazar. Trop Georg Med 1991:43:357-362.

8. World Health Organization. Global health situation in selected infections and parasitic diseases due to identification organisms. Wkly Epidemiol Rec 1993;641648.

9. Benjamin B, Annobil SH, Bassuni WA. Diagnostic and management problems in childhood visceral leishmaniasis in south-western Saudi Arabia. Ann Trop Paediatr 1994;14:7-13.

10. Ali A, Ashford RW. Visceral leishmaniasis in Ethiopia. IV. Prevalence, incidence and relation of infection to disease in an endemic area. Ann Trop Med Parasitol 1994; 88:289-293.

11. Williams JE. Leishmania, trypanosoma. In: Gillespie SH, Hawkey PM, editors. Medical parasitology. A practical approach. UK: Oxford University Uress; 1995.

12. Singh k, Singh R, Parija SC, Faridi MM, Bhatta N. Clinical and laboratory study of kala-azar in children in Nepal. I Trop Pediatr 1999:45:95-107. 
13. Haidar NA, Dai ABL, El-Sheikh AM. Visceral leishmaniasis in children in the Yemen. Saudi Med J 2001; 22:516-519.

14. Kafetzis DA. An overview of paediatric leishmaniasis. University of athens second department of paediatrics, " $\mathrm{P}$ and A. Kyriakou" Children's Hospital, Athens, Greece. 2003;49:31-38.

15. Sinha AK, Rijal S, Karki P, Majhi S. Incidence of megaloblastic anaemia and its correction in leishmaniasis- a prospective study at BPKIHS hospital, nepal. Indian J pathol Microbiol 2006;49:528-531.

16. Rai ME, Muhammad Z, Sarwar J, Qureshi AM. Haematological findings in relation to clinical findings of visceral leishmaniasis in Hazara division. J Ayub Med Coll Abbottabad 2008;20:40-43.

17. Saqur I M.AL, Abed BK, Alswidi FAK. Comparative study of focuses of visceral leishmaniasis infections in Baghdad and wasit Governerates. J Dohuk Univ 2008;11:164-172.

18. Hamid GA, Gobah GA. Clinical and haematological manifestation of visceral leishmaniasis in Yemeni children. Turk J Hematol 2009;26:25-28.

19. Canatan D, Comak E, Kuybulu AE. Visceral leishmaniasis of childhood. J Pediatr Inf 2009;3:109-111.

20. Patrela R, Kuneshka L, Foto E, Zavalani F, Grador L. Pediatric visceral leishmaniasis in albania: A retrospective analysis of 1,210 consecutive hospitalized patients (2009). PLOS Negl Trop Dis $2010 ; 4: 40-43$.

21. Pace D, Williams TN, Grochowska A, Betts A, Montalto SA, Boffa MJ, Vella C. Manifestation of pediatric leishmaniasis infantum infections in malta. Travel Med Infect Dis 2011;9:37-46.

\section{Citing this article}

Agrawal Y, Sinha AK, Upadhyaya P, Kafle SU, Rijal S,.Khanal B. Hematological profile in visceral leishmaniasis. Int J Infect Microbiol 2013;2(2):3944. 